\title{
«ЗЕЛЕНАЯ» ЭКОНОМИКА КАК НОВАЯ ЭКОНОМИЧЕСКАЯ МОДЕЛЬ РАЗВИТИЯ СОВРЕМЕННОГО ГОРОДА
}

\author{
Майснер Татьяна Николаевна \\ к.ф.н. \\ ФГБОУ ВО «ЮРГПУ (НПИ) \\ им. М.И. Платова»
}

\begin{abstract}
Аннотация: Статья посвящена исследованию процесса развития «зеленой» экономики в качестве новой экономической модели современной урбанистической цивилизации. Достижение устойчивого развития современного города связано с качеством его экологической среды, которое возможно только при реализации технологий «зелёной» экономики.

Ключевые слова: «зелёная» экономика, городская инфраструктура, экосистема города, экогород, экосити, экологизация производства, устойчивое развитие города.
\end{abstract}

\section{«GREEN» ECONOMY AS A NEW ECONOMIC MODEL FOR THE DEVELOPMENT OF A MODERN CITY}

\section{Meisner Tatyana Nikolaevna}

\begin{abstract}
The article is devoted to the study of the development process of the "green" economy as a new economic model of modern urban civilization. Achieving sustainable development of a modern city is associated with the quality of its ecological environment, which is possible only with the implementation of "green" economy technologies.
\end{abstract}

Key words: "green" economy, urban infrastructure, city ecosystem, eco-city, greening of production, sustainable development of the city.

В Докладе ООН о Целях в области устойчивого развития отмечается, что сегодня «более половины населения мира проживает в городах. Прогнозируется, что к 2030 году доля городских жителей достигнет 60 процентов» [6]. Выступая драйвером развития цивилизации, города стали 
акторами деградации природной среды и создали массу экологических проблем. Увеличение нагрузки на городскую инфраструктуру и экосистему городского пространства актуализирует вопрос о дальнейшем развитии городского хозяйства и возможностях «экологической» реконструкции городов с целью сделать их безопасными для жизни людей и окружающей среды.

В настоящее время большинство городов с одной стороны, представляют собой центры активной экономической деятельности, являются сосредоточением научно-технологических достижений и местом культурной жизни людей, а с другой стороны, представляют зоны экологического неблагополучия - мусорные свалки, наличие городских трущоб и других источников санитарно-эпидемиологических угроз.

Основным источником деградации городской среды считается сфера экономики, функционирование которой осуществляется, во-первых, за счет природных ресурсов, во-вторых, сопровождается появлением промышленных отходов, влекущих за собой загрязнение природной среды.

Очевидно, что сложившаяся модель экономической деятельности, опирающаяся на идеологию либерализма и установки общества потребления, только усугубляет экологическое неблагополучие городской среды. Поэтому необходимы принципиально новые подходы к организации производства и ограничению потребления в обществе. Один из способов, который обладает потенциалом для значительного снижения антропогенной нагрузки на биосистему, является развитие «зеленой» экономики.

Термин «зеленая» экономика как ориентир для стратегического развития человечества появился в документах $\mathrm{OOH}$ по охране окружающей в 2000 году и определялся, как форма организации хозяйственной деятельности, «которая повышает благосостояние людей и обеспечивает социальную справедливость, и при этом существенно снижает риски для окружающей среды и обеднение природы» [5]. Позднее данный термин активно использовался в обсуждениях Всемирного экономического форума (Давос, 2010 г.), на конференции ООН по устойчивому развитию «Рио+20».(Рио-де-Жанейро, 2012 г.). В рамках этих мероприятий уже складывается понимание того, что рыночную модель экономики необходимо менять на «зеленую» экономику, которая сможет обеспечить сохранность и улучшение качества окружающей среды. В 2009 году в официальной декларации государств - членов Организации экономического 
сотрудничества и развития (ОЭСР) был заявлен переход к технологиям «зеленой» экономике, а с 2011 г. началась практика их реализации.

Более того в проекте ООН Цели устойчивого развития (2016 г.), определены задачи по обеспечению безопасности и экологической устойчивости городов и населенных пунктов, их переходу к рациональным моделям потребления и производства. Решение этих задач связано с двумя ключевыми направлениями: а) ужесточение экологического контроля над техногенными процессами, влияющими на изменение климата (внедрение «зеленых» технологий); б) реализация политики энергосбережения, «в том числе за счет ужесточения норм энергопотребления, а также технологических и структурных сдвигов» [9, с. 68].

По мнению специалистов, данный курс «отчетливо прослеживается в экономической политике европейских лидеров «зеленого» экономического роста - Великобритании и Германии - правительства и деловые круги которых рассматривают производство экологически чистой и низкоуглеродной продукции, оборудования для защиты окружающей среды, технологий снижения климатических рисков и адаптации к последствиям климатических изменений как наиболее перспективное направление национального экспорта» $[13$, с. 5$]$.

Так или иначе достижение устойчивого развития современного города связано с качеством его экологической среды. Достижение последнее возможно при реализации модели «зелёной» экономики.

Термин «зелёная» экономика впервые появился в работе английских ученых Д. Пирса, А. Маркандии и Э. Барбиера «План для зелёной экономики» в 1989 г., в которой речь шла о значимости экономического содействия в реализации экологической политики [18]. Эти идеи получили развитие в 90-х гг. ХХ века в ходе обсуждения назревших экологических проблем, связанных с угрозами климатических изменений, уменьшения озонового слоя, массового уничтожения лесных зон и истощения ресурсов в развивающихся странах.

Сегодня в научном сообществе идет активное обсуждение проблем «зеленой» экономики, формируется понятийный аппарат в этой области исследования, выстраивается структура данной модели экономического развития общества. 
Зарубежные авторы предлагают понимать под «зеленой» экономикой устойчивую систему развития экологии, экономики и общества. По мнению К. Буркарта, в системе «экология-экономика-общества» элементом, обеспечивающим ей стабильность является экология, тогда как экономика представляет собой наименее устойчивый компонент данной системы [17]. Поэтому дальнейшее существование этой системы возможно только при условии доминирования в ней экологического компонента.

Аналогичной позиции придерживаются и такие исследователи, как Дж. Андреа, К. Бернс, Дж. Туза, которые связывают дальнейшее устойчивое развитие человечества исключительно с развитием «зеленой» экономики, которая только и «способна стабилизировать экономические системы и сбалансировать интересы человека, природы и эффективного использования ресурсов» $[16$, с. 84$]$.

В отечественном научном дискурсе проблематика «зеленой» экономикой рассматривается в работах А.И. Бексултановой, В.С. Бочко, Т.В. Захаровой, Г.С. Розенберг, Г.Э. Кудиновой и др.[1; 3; 7; 14]. Авторы утверждают, что «время неспешного перехода к «зеленой» экономике прошло - сегодня в ответ на последствия кризиса и в связи с потерей рабочих мест и необходимостью смягчения климатических изменений требуется быстрый планетарный переход к «зеленой» экономике. Цели ее весьма амбициозны, она способна обеспечить синергизм между тремя основными уровнями развития - экономическим ростом, социальным благополучием и охраной окружающей среды и здоровья людей» [7, с. 31].

Рассматривая структуру «зеленой» экономики, специалисты в качестве базового ее элемента называют «зеленую» промышленность, которая есть «процесс промышленного производства и совершенствования, осуществляющийся без уничтожения систем природы, не приводит к неблагоприятным результатам, которые влияют на здоровье человека» [8].

Исследователи видят развитие этой промышленности в следующем направлении [1]:

1) экологизация производства за счет рационального использования природных ресурсов;

2) создание «зеленых» отраслей промышленности за счет инкорпорирования в них экотехнологий и развития различных экологических услуг. 
Очевидно, что практическая реализация стратегии «зеленой» экономики в городское хозяйство связанна с инновационными технологиями и развитием новых отраслей промышленности, отвечающих требованиям экологической безопасности.

В настоящее время понятие «зеленая» экономика вошло в научный дискурс, который представлен различными подходами к пониманию еe сущности, структуры, возможностей реализации в пространстве современного города и пр. Подходы по данной проблеме можно классифицировать на несколько кластеров: экономический, технологический и аксиологический.

1) Экономический подход к «зеленой» экономике разрабатывается в работах, как зарубежных, так и отечественных ученых. Анализируя возможности реализации новой модели экономики в развивающихся странах, китайские ученые выявили связь между практическим воплощением этой модели и методами «зеленого» управления [19]. По их мнению, «зеленая» экономика возможна только при условии «зеленого» управления. Российские исследователи связывают переход к «зеленой» экономики со сменой нынешней модели сугубо рыночной экономики, которая продемонстрировала свою несостоятельность, как в плане природопользования, так и возможностей вывода стран из мирового экономического кризиса [7]. Представители экономического подхода к «зеленой» экономике видят дальнейшее развитие исключительно на основе «создания новых экологически чистых отраслей за счет спроса со стороны государства и формирования нового спроса и новой культуры потребления со стороны общества» [4, с. 132].

2) Технологический подход в качестве ключевого фактора диверсификации хозяйственной деятельности видит технологические инновации, обеспечивающие «создание экологически чистых промышленных и продовольственных товаров» [3, с. 114]. По мнению сторонников этого подхода, эффективное решение экологических проблем лежит сугубо в плоскости развития науки и технологий: «экологически опасные технологические процессы должны быть ресурсосберегающими и экологизированными в рамках системной экологизации производства» [12, с. 21]. Прежде всего речь идет о создании низкоотходных технологических производств с максимально замкнутыми циклами, разработка и внедрение систем утилизации и обезвреживания отходов, глубокой очистки сточных вод и т.д. 
3) Аксиологический подход связывает развитие «зеленой» экономики с формированием в социуме экологической культуры, которая и станет основой трансформации нынешней экономической модели, опирающейся на ценности либерализма и рыночного фундаментализма, на экогуманистическую модель отношений в системе «экология-экономика-общество». По мнению специалистов, данный подход «декларирует базовые ценности «зеленой» экономики: гармонизация отношений через взаимодействие человечества и биосферы, развитие человечества в границах законов развития биосферы, осознанные ограничения на потребление ресурсов биосферы и удовлетворение потребностей с учетом возможностей биосферы» [4, с. 136].

Надо отметить, что вышеперечисленные подходы к анализу «зеленой» экономики и ее возможностей в решении экологических проблем являются концептуальными только на интегративной основе, поскольку практическая реализация модели «зеленой» экономики предполагает комплексный подход, включающий экономические, технологические и аксиологические способы обеспечения экологической безопасности урбанизированных территорий.

В целом, «зеленую» экономику следует рассматривать как новую экономическую модель, которая должна прийти на смену нынешней модели, где доминируют принципы либеральной идеологии.

Исследователи отмечают, что именно экологическая экономика лежит в основе появления экогородов. Следует признать, что процесс создания экополисов начался с 60-х гг. XX в. в США и Европе, то есть еще до появления современных инновационных технологий. Однако первыми и наиболее эффективными в создании экологически урбанизированных территорий стали Швеция и Дания.

Если на протяжении десятилетий идея экогорода носила преимущественно утопический характер, то уже на «Глобальном Форуме-94» был представлен первый в мировой практике реальный проект экогорода в Швеции. Речь идет о городе Мальмё, который примерно за 10 лет смог стать самым экологичным городом страны.

История Мальмё такова: изначально он представлял из себя портовый город, промышленность которого была ориентирована на кораблестроение. По сути это был моногород, благополучие которого зависело от одной отрасли производства, рентабельность которой, с начала 90-х годов XX века стремительно снижалась. Именно это заставило власти города закрыть 
неконкурентоспособное производство. Это повлекло за собой безработицу и деградацию городской территории, которая превратилась в зону заброшенных промышленных предприятий. Понимание того, что промышленная ориентация города уже не решит его социальные проблемы, заставило власти и жителей города искать альтернативные способы выживания. Проект по решению проблем депрессивного города прежде всего включал развитие новой инфраструктуры города и преобразования промышленно-портовых зон в новые эко-районы. Причем жилищное строительство велось исключительно экологическими материалами, которые обладали повышенной способностью сохранения тепла в помещении, что значительно сокращало затраты на их отопление в зимнее время. Также для получения энергии здесь массово используются солнечные панели и ветровые станции.

Важным направлением экологизации городской территории Мальмё стала сортировка и переработка бытовых отходов. Мусор идёт на переработку для дальнейшего употребления и получения дополнительного источника энергии, поскольку «3 тонны отходов содержат столько же энергии, сколько содержит 1 тонна ископаемого топлива» [15, с. 200]. Тем самым, «утилизация твердых отходов обеспечивает $20 \%$ тепла в шведских домах. Сегодня таким образом отапливается почти 900 тысяч шведских домохозяйств» [10, с. 66].

Еще одним направлением в экологизации Мальмё стало развитие велосипедного транспорта. В настоящее время в городе «более 400 километров велодорожек и несколько тысяч парковочных мест под велосипеды» [2]. Кроме этого, большинство автобусов работает на биотопливе. Зеленые технологии реализуются в архитектурных строениях, в частности, в городе большое количество зеленых крыш, где располагаются природные зону и системы сбора дождевой воды.

По мнению специалистов, город Мальме является примером именно целостного экосити, в котором в полной мере были реализованы принципы «зеленой» экономики, социально-технической экологии. Создание экологичного городского пространства достигалось «с помощью применения новых строительных технологий, развития общественного транспорта, перехода автовладельцев на гибридный транспорт и электрокары, продвижения альтернативной энергетики и энергосберегающих технологий» [11, с. 315].

Таким образом очевидно, что девирсификация хозяйственной деятельности, применение инновационных технологий для получения 
возобновляемых энергетических ресурсов, а также формирование экологической культуры у населения, способствовало успешной реализации проекта экосити в шведском городе Мальме, который и сегодня входит в топ-6 самых экологичных городов мира, наряду с Дублином (Ирландия), Таллином (Эстония), Хиллеродом (Дания), Гамбургом (Германия), Аугустенборгом (Дания) [11].

В настоящее время стремление к реализации модели «зеленой» экономики наблюдается во многих городах мира, которые стремятся стать экосити или экополисами. Успешный опыт преобразования традиционных городов в экосити имеется как в ряде европейских стран и США, так и в ОАЭ, Китае, Японии, Новой Зеландии.

Таким образом, развитие «зеленой» экономики кардинально трансформирует инфраструктуру города, основными элементами которой становятся: а) «зеленое» строительство, предполагающее использование энергосберегающих материалов, б) «зеленый» транспорт, работающий на возобновляемых ресурсах; в) рациональное управление отходами, применение сортировки и вторичной переработки отходов производства или мусора; г) комплексное озеленение городской территории (расширение природных зон, «зеленые» крыши и т. п.).

Невзирая на то, что в ряде развитых стран идет процесс реорганизации экономики на основе «зеленых» технологий и строительство экосити, состояние большинства современных городов характеризуется деградацией природной среды, что, конечно, ограничивает возможности дальнейшего развития городской территории, значительно ухудшает ее качество и, соответственно, здоровье населения.

\section{Список литературы}

1. Бексултанова А.И. Теоретические аспекты «зеленой» экономики // International scientific review. 2016. № 5 (15). С.64-66.

2. Биотопливо, велосипеды и зеленые крыши: как развивается шведский «город будущего» Мальме [Электронный ресурс] https://www.capital. ua/ru/ publication/86315-biotoplivo-velosipedy-i-zelenye-kryshi-kak-razvivaetsya-shved skiy- gorod -buduschego-malme\#ixzz75PGhzzgS (дата обращения: 10.06.2021). 
3. Бочко В.С. Зеленая экономика: вторая вечная проблема человечества // Вестник УрФУ. Сер. Экономика и управление. 2014. № 3. С.113-119.

4. Вукович Н. А. «Зеленая» экономика: определение и современная эколого-экономическая модель // Вестник УрФУ. Серия экономика и управление. 2018. Том 17. № 1. С.128-145.

5. Декларация тысячелетия Организации Объединенных Наций. Принята 8 сентября 2000 года Генеральной Ассамблеей ООН (Резолюция № A/RES/52/2). 2000. [Электронный ресурc] URL: http://www.un.org/ru/ documents/ decl-conv / declarations / summitdecl.shtml (дата обращения: 11.10.2021).

6. Доклад о Целях в области устойчивого развития, 2016 год [Электронный pecypc] / https://unstats.un.org/sdgs/report/2016/The\%20Sus tainable \%20Development\%20Goals\%20Report\%202016_Russian.pdf (дата обращения: 16.10. 2021).

7. Захарова Т. В. «Зеленая» экономика как новый курс развития: глобальный и региональный аспекты // Вестник Томского государственного университета. Экономика. 2011. № 4 (16). С.28-38.

8. Инициатива ЮНИДО в области «зеленой» промышленности по устойчивому промышленному развитию [Электронный ресурс]. ООН по промышленному развитию. Вена: ЮНИДО, 2011. [Электронный ресурс] http://www.greenindustryplatform.org/wp-content/uploads/2014/06/UNIDO-GreenIndustryInitiative-for-Sustainable-Industrial-Development_RU.pdf (дата обращения: 17.10. 2021).

9. Кузнецова Г. В. Ответственное инвестирование и устойчивое развитие: мировой и российский опыт // Российский внешнеэкономический вестник. 2016. № 6. С.66-78.

10. Осипов А. Б., Козырева М. С. Решение эколого-экономических проблем переработки отходов в рамках концепции «зеленой» экономики // Технико-технологические проблемы сервиса. 2018. №2(44). С.61-67.

11. Пахомова А. И. Современные экогорода: опыт и перспективы развития // Вестник Иркутского государственного технического университета. 2010. №5 (45). С. 312-316.

12. Половняк В.К., Фридланд С. В. Современные технические и технологические подходы к решению экологических проблем // Вестник Казанского технологического университета. 2009. № 4. С.17-25. 
13. Порфирьев Б. Н. «Зеленый» фактор экономического роста в мире и в России // Проблемы прогнозирования. 2018. № 5 (170). С. 3-12.

14. Розенберг Г. С., Кудинова Г.Э. На пути к «зеленой» экономике (знакомясь с докладом ЮНЕП к «Рио $+20 ») / /$ Биосфера. 2012. Т. 4. № 3. C. $245-250$

15. Чернышов В. И., Рей Санчес Д. В. Обращения с твердыми бытовыми отходами в Швеции // Международный журнал гуманитарных и естественных наук. 2016. № 1. С. 199-201.

16. Andrea, J. J., Burns, C., Touza, J. Renewable Energy as a Luxury? A Qualitative Comparative Analysis of the Role of the Economy in the EU's Renewable Energy Transitions During the 'Double Crisis'// Ecological Economics, 2017. Vol. 142. P. 81-90.

17. Burkart K. How Do You Define the 'Green' Economy? MNN [Электронный ресурc] URL: Mother Nature Network. Available at: http://www. $\mathrm{mnn}$. com/greentech/research-innovations/blogs/ how-do-you-define-the-green-econo ту. (дата обращения: 14.09.2021).

18. Pearce D. W. Markandya A. and Barbier E. R. Blueprint for a Green Economy. London. Earthscan Publications Ltd. 1989. 192 p.

19. Yang J., Zhang F., Jiang X., Sun W. Strategic Flexibility, Green Management, and Firm Competitiveness in an Emerging Economy // Technological Forecasting and Social Change. 2015. Vol. 101. P. 347-356.

(C) Т.Н. Майснер, 2022 